\title{
PERSEPSI MEMPENGARUHI RENDAHNYA PEMAKAIAN KONTRASEPSI IMPLAN
}

\author{
Reznita Adityani D. Akhmad, Djuhadiah Saadong, Afriani ${ }^{\bowtie}$, Hidayati \\ Jurusan Kebidanan Poltekkes Kemenkes Makassar
}

\begin{tabular}{l}
\hline ARTICLE INFO \\
\hline Article history \\
Submitted : 2021-10-19 \\
Revised : 2022-01-05 \\
Accepted : 2022-01-25 \\
Keywords: \\
Implant \\
Perception \\
Socioeconomic \\
Anxiety
\end{tabular}

\section{Kata Kunci:}

Implan

Persepsi

Sosial Ekonomi

Kecemasan

\begin{abstract}
Indonesia, there are relatively few users of contraceptive implant methods compared to other types of contraception, although implants have a higher level of effectiveness than other contraceptives. The government has made various efforts but to no avail. The purpose of the study was to determine the factors that influence the low use of contraceptive implants at the Minasa Upa Health Center in Makassar City. The research method is an analytic survey with a "cross-sectional study" method and sampling using a simple random sampling technique of 67 people. The study was conducted in MarchMay 2021 using a questionnaire. Statistical analysis was performed using the Chisquare test $=0.05$. The results showed that the phi value of perceived significance was $\mathrm{p}=0.001(\mathrm{p}>0.05)$, socioeconomic $\mathrm{p}=0.756(\mathrm{p}>0.05)$, and the anxiety factor was $\mathrm{p}=0.369$ $(p>0.05)$. So it is known that perception has a significant relationship with the low use of contraceptive implants methods, while socioeconomic and anxiety factors do not have a significant relation. Therefore, it is recommended for health workers to conduct regular counseling about contraception, especially contraceptive implant methods, to increase mothers' knowledge so that negative perceptions of contraceptive implant methods can be reduced.

Di Indonesia pengguna kontrasepsi metode implan cenderung relatif lebih sedikit dibandingkan dengan jenis metode kontrasepsi lainnya.walaupun implan memilki tingkat efektifitas yang lebih tinggi dibandingkan kontrasepsi lainnya. Pemerintah telah melakukan berbagai upaya namun belum berhasil. Tujuan penelitian untuk mengetahui faktor-faktor yang mempengaruhi rendahnya pemakaian kontrasepsi implan di Puskesmas Minasa Upa Kota Makassar. Metode penelitian bersifat survey analitik dengan metode "cross sectional study " dan pengambilan sampel menggunakan teknik simple random sampling sebanyak 67 orang. Penelitian dilakukan bulan Maret-Mei 2021 menggunakan kusioner. Analisis statistik dilakukan secara bivariat menggunakan uji Chi-square $\alpha=0,05$. Hasil penelitian diketahui bahwa phi nilai signifikansi persepsi $\mathrm{p}=0,001(\mathrm{p}>0,05)$, sosial ekonomi $\mathrm{p}=0,756(\mathrm{p}>0,05)$, dan faktor kecemasan $\mathrm{p}=0,369$ ( $>0,05)$. Sehingga diketahui bahwa persepsi mempunyai hubungan signifikan dengan rendahnya pemakaian kontrasepsi implan, sedangkan sosial ekonomi dan faktor kecemasan tidak memilki hubungan yang signifikan. Oleh sebab itu, disarankan petugas kesehatan melakukan penyuluhan yang rutin mengenai kontrasepsi khususnya implan untuk menambah pengetahuan ibu sehingga persepsi negatif terhadap kontrasepsi implan dapat diatasi.
\end{abstract}

This is an open access article under the CC BY-SA license:

\section{Afriani}

Jurusan Kebidanan Poltekkes Kemenkes Makassar Telp. 081342412307

Email: afriani@poltekkes-mks.ac.id

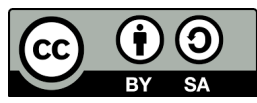

\section{PENDAHULUAN}

Menurut World Health Organization (WHO) implan adalah kapsul atau batang berisi hormon yang dimasukkan ke bawah kulit di lengan atas wanita. Mekanisme dari implan ini ialah dengan menebalkan lendir serviks dan mencegah ovulasi pada sekitar pertengahan dari siklus menstruasi (World Health Organization (WHO), 2015). Menurut Badan Kependudukan dan Keluarga Berencana Nasional (BKKBN) implan adalah alat kontrasepsi berbentuk kapsul lunik kecil yang mengandung hormon diletakkan tepat di bawah kulit lengan atas yang memberikan perlindungan jangka panjang terhadap kehamilan (BKKBN, 2017).

Di Indonesia pengguna kontrasepsi metode implan cenderung relatif lebih sedikit dibandingkan dengan jenis metode kontrasepsi 
lainnya. Menurut BKKBN pada tahun 2019 persentasi pengguna kontrasepsi implan hanya sebesar 7,4 \% sangat jauh berbeda dengan metode suntik dan pil yang masing-masing tercatat sebesar $63,7 \%$ dan pil sebesar $17,0 \%$. Walaupun pengguna kontrasepsi implan naik sebesar $0,2 \%$ dari tahun sebelumnya yang hanya tercatat sebesar $7,2 \%$ saja. Walaupun demikian kenaikan ini masih relatif sangat jauh berbeda dari metode kontrasepsi lainnya. Di Sulawesi Selatan sendiri pengguna kontrasepsi implan hanya sebesar $79.889 \quad(10,3 \%)$, walaupun angka ini melebihi rata-rata pengguna kontrasepsi implan secara nasional tapi tidak dapat dipungkiri bahwa angka ini masih terbilang rendah (Kemenkes RI, 2019).

Rendahnya pemakai kontrasepsi Implan ini juga mencakup Kota Makassar. Menurut data Dinas Kesehatan tahun 2017 di Kota Makassar pengguna kontrasepsi implan hanya sekitar 12.717 (7,3\%) saja, persentasi pengguna metode kontrasepsi tertinggi ialah suntik dengan angka pengguna sebesar $89.499(51,70 \%)$ dan dikuti oleh pil sebesar 54.791 (31,65\%) (Dinkes Kota Makassar, 2017).

Menurut data dari Puskesmas Minasa Upa pada bulan januari sampai desember 2019 dengan pengguna kontrasepsi aktif sebanyak 3.253 akseptor, dimana pengguna tertinggi adalah metode suntikan dengan angka 1.393 (29\%) dikuti oleh pil sebanyak $1.014(21,3 \%)$ Intrauterine Device (IUD) sebanyak 390 $(7,5 \%)$, implan sebanyak $435(9,1 \%)$, dan Metode Operasi Wanita (MOW) sebanyak 21 $(0,4 \%)$.

Metode kontrasepsi implan yang merupakan salah satu dari metode yang tersedia pada saat ini, nampaknya kurang diminati masyarakat khususnya pasangan usia subur meskipun efektifitas kontrasepsi implan ini sangat tinggi yaitu kegagalannya $0,2-1$ kehamilan per 100 perempuan (Affandi et al., 2014). Pemerintah telah melakukan upaya untuk mengatasi, hal ini yaitu dengan membentuk kembali program Kependudukan Keluarga Berencana dan Pembangunan Keluarga (KKBPK) yang disebut dengan "Kampung KB”. Kampung KB adalah program Keluarga Berencana yang terkonsep dan terpadu dengan program-program pembangunan lainnya, yang terdiri dari pendidikan, kesehatan, ekonomi, dan program lainnya (Mardiyono, 2017).

Program kampung $\mathrm{KB}$ meliputi kegiatan sosialisasi program $\mathrm{KB}$, sosialisasi berbagai macam alat kontrasepsi dan keuntungannya, pelayanan kontrasespi serta safari KB Metode Kontrasepsi Jangka Panjang (MJKP) gratis, dengan adanya program ini dimaksudkan agar pemakaian KB MKJP khususnya implan dapat ditingkatkan. Namun, faktanya sampai saat ini minat terhadap kontrasepsi implan tidak mengalami perubahan yang berarti.

Banyak faktor yang menyebabkan rendahnya minat ibu dalam menggunakan kontrasepsi implan. Menurut penelitian yang dilakukan (Saad, 2018), mengenai faktor-faktor yang berhubungan dengan penggunaan alat kontrasepsi implan di Puskesmas Batulappa Kab. Pinrang menyatakan bahwa ada hubungan antara pengetahuan dan dukungan suami terhadap minat ibu menggunakan kontrasepsi implan. Hal ini juga sejalan dengan penelitian (Rahmi \& Hadi, 2020) yang juga menambahkan satu faktor yaitu peran tenaga kesehatan. Sedangkan faktor sosial budaya tidak termasuk ke dalamnya.

Penelitian lainnya yang dilakukan (Lestari \& Rachmadini, 2019) mengenai faktorfaktor yang berhubungan dengan rendahnya minat ibu terhadap penggunaan implan didapatkan ada hubungan antara usia, paritas, tingkat pendidikan, dan dukungan suami terhadap minat ibu menggunakan kontrasepsi Implan. Berdasarkan uraian tersebut maka peneliti tertarik untuk meneliti tentang faktorfaktor yang mempengaruhi rendahnya pemakaian kontrasepsi implan.

\section{METODE PENELITIAN}

\section{Jenis Penelitian}

Jenis penelitian ini adalah adalah survey analitik dengan menggunakan pendekatan cross sectional study.

\section{Lokasi dan Waktu Penelitian}

Penelitian dilaksanakan di Puskesmas Minasa Upa Kota Makassar, pada bulan Maret - Mei 2021.

\section{Populasi dan Sampel}

Populasi dalam penelitian ini adalah seluruh akseptor KB yang berkunjung di Puskesmas Minasa Upa periode Januari sampai November 2020 sebesar 312 akseptor KB. Sampel dalam penelitian ini adalah akseptor KB yang tidak menggunakan kontasepsi implan yang memenuhi kriteria inklusi yaitu ibu yang 
bersedia menjadi responden dengan menandatangani lembar persetujuan (informed consent) dan ibu yang sedang menggunakan kontrasepsi hormonal.

\section{Pengumpulan Data}

Pengumpulan data dilakukan menggunakan kusioner dengan 3 jenis kuesioner yaitu kuesioner persepsi ibu, sosial ekonomi, dan kecemasan ibu. Kuesioner persepsi berisi 10 pernyataan dengan menggunakan skala likert yaitu skor 4 untuk pilihan sangat setuju, skor 3 untuk pilihan setuju, skor 2 untuk pilihan kurang setuju dan 1 untuk pilihan tidak setuju.

Kuesioner sosial ekonomi berisi 2 pertanyaan mengenai pendapatan dan Pendidikan ibu. Sedangkan kusioner kecemasan ibu berisi 8 pernyataan dengan menggunakan skala guttman yaitu dengan pilihan jawaban ya atau tidak.

\section{Pengolahan dan Analisis Data}

Pengolahan data dilakukan dengan menggunakan komputer program Statistical Package For Social Science (SPSS) dengan tahapan editing, coding, entry data, cleaning data. Penyajian data dalam bentuk tabel distribusi frekuensi.

Analisis data yang digunakan dalam penelitian ini adalah analisis univariat dan bivariat. Analisis univariat dalam penelitian ini dianalisa dengan menggunakan tabel distribusi frekuensi dan persentase dari masing-masing variabel yang diteliti. Sedangkan analisis bivariat digunakan untuk menguji hipotesis dengan menentukan hubungan antar variabel. Adapun uji yang digunakan adalah uji statistic chi-square untuk melihat hubungan kedua variabel dengan nilai $\mathrm{p}<0,05$.

\section{HASIL PENELITIAN}

Penelitian ini menggunakan data primer yang didapatkan melalui pengisian kuesioner. Data yang telah diperoleh kemudian diolah dengan menggunakan analisis uji Chi Square dan disajikan dalam bentuk tabel frekuensi dan crosstable (tabulasi silang) sesuai dengan tujuan penelitian dan disertai narasi sebagai penjelasan tabel. Adapun hasil penelitian yang telah dilakukan diuraikan sebagai berikut:

Tabel 1. Distribusi Frekuensi Responden berdasarkan Persepsi Ibu, Sosial Ekonomi, Kecemasan, dan Jenis Kontrasepsi

\begin{tabular}{lcc}
\hline \multicolumn{1}{c}{ Kategori } & Frekuensi (n) & Persen (\%) \\
\hline Persepsi & & \\
Negatif & 37 & 55,2 \\
Positif & 30 & 44,8 \\
Jumlah & 67 & 100 \\
\hline Sosial Ekonomi & & \\
Kurang & 35 & 52,2 \\
Cukup & 32 & 47,8 \\
Jumlah & 67 & 100 \\
\hline Kecemasan & & \\
Tidak cemas & 54 & 80,6 \\
Cemas & 13 & 19,4 \\
Jumlah & 67 & 100 \\
\hline Jenis Kontrasepsi & & \\
Suntik & 39 & 58,2 \\
Pil & 28 & 41,8 \\
Jumlah & 67 & 100 \\
\hline Sur Dat Prime Tan & &
\end{tabular}

Sumber: Data Primer Tahun 2020

Berdasarkan tabel 1. menunjukkan bahwa dari 67 sampel mayoritas responden memiliki persepsi negatif terhadap kontrasepsi implan dengan jumlah 37 sampel $(55,2 \%)$ sedangkan responden yang memiliki persepsi positif berjumlah 30 sampel $(44,8 \%)$. Dari 67 sampel mayoritas responden memiliki sosial ekonomi yang kurang jumlah 35 sampel 
$(52,2 \%)$ sedangkan responden yang memiliki sosial ekonomi yang cukup berjumlah 32 sampel $(47,8 \%)$.

Dari 67 sampel mayoritas responden merasa tidak cemas dengan jumlah 54 sampel $(80,6 \%)$ sedangkan responden yang merasa cemas berjumlah 13 sampel $(19,4 \%)$. Dari 67 sampel mayoritas responden menggunakan kontrasepsi suntik dengan jumlah 38 sampel $(58,2 \%)$ sedangkan responden yang menggunakan kontrasepsi pil berjumlah 28 sampel (41,8\%).

Tabel 2. Hubungan antara Persepsi, Sosial Ekonomi, dan Kecemasan dengan Rendahnya Pemakaian Kontrasepsi Implan

\begin{tabular}{|c|c|c|c|c|c|c|c|}
\hline \multirow{3}{*}{$\begin{array}{l}\text { Variabel } \\
\text { Penelitian }\end{array}$} & \multicolumn{4}{|c|}{$\begin{array}{c}\text { Rendahnya Pemakaian } \\
\text { Kontrasepsi Implan }\end{array}$} & \multirow{2}{*}{\multicolumn{2}{|c|}{ Total }} & \multirow{3}{*}{ Statistik } \\
\hline & \multicolumn{2}{|c|}{ Suntik } & \multicolumn{2}{|c|}{ Pil } & & & \\
\hline & $n$ & $\%$ & $\mathrm{n}$ & $\%$ & $\mathbf{N}$ & $\%$ & \\
\hline \multicolumn{8}{|l|}{ Persepsi } \\
\hline Negatif & 28 & 75,7 & 9 & 24,3 & 37 & 100 & \multirow{3}{*}{$\mathrm{P}=0,001$} \\
\hline Positif & 11 & 36,7 & 19 & 63,3 & 30 & 100 & \\
\hline Jumlah & 39 & 58,2 & 28 & 41,8 & 67 & 100 & \\
\hline \multicolumn{8}{|l|}{ Sosial Ekonomi } \\
\hline Kurang & 21 & 60 & 14 & 40 & 35 & 100 & \multirow{3}{*}{$\mathrm{P}=0,756$} \\
\hline Cukup & 18 & 56,3 & 14 & 43,8 & 32 & 100 & \\
\hline Jumlah & 39 & 58,2 & 28 & 41,8 & 67 & 100 & \\
\hline \multicolumn{8}{|l|}{ Kecemasan } \\
\hline Cemas & 9 & 69,2 & 4 & 30,8 & 13 & 100 & \multirow{3}{*}{$\mathrm{P}=0,369$} \\
\hline Tidak Cemas & 30 & 55,6 & 24 & 44,4 & 54 & 100 & \\
\hline Jumlah & 39 & 58,2 & 28 & 41,8 & 67 & 100 & \\
\hline
\end{tabular}

Berdasarkan tabel 2. menunjukkan bahwa responden yang menggunakan kontrasepsi suntik memiliki persepsi yang positif berjumlah 11 orang $(36,7 \%)$ dan yang memiliki persepsi negatif sebanyak 28 orang $(75,7 \%)$. Sedangkan responden yang menggunakan kontrasepsi pil memiliki persepsi positif berjumlah 19 orang $(63,3 \%)$ dan yang memiliki persepsi negatif berjumlah 9 orang (24,3\%). Dari hasil uji statistik Chi-Square diperoleh nilai $\mathrm{p}=0,001<$ dari $\alpha=0,05$ sehingga hipotesis alternatif $(\mathrm{Ha})$ diterima yang artinya ada hubungan antara persepsi dengan rendahnya pemakaian kontrasepsi implan.

Responden yang menggunakan kontrasepsi suntik memiliki sosial ekonomi yang cukup berjumlah 18 orang $(56,3 \%)$ dan yang memiliki sosial ekonomi kurang sebanyak 21 orang $(60 \%)$. Sedangkan responden yang menggunakan kontrasepsi pil memiliki sosial ekonomi yang cukup berjumlah 14 orang (40\%) dan yang memiliki sosial ekonomi yang kurang berjumlah 14 orang $(43,8 \%)$. Dari hasil uji statistik Chi-Square diperoleh nilai $\mathrm{p}=0,756>$ dari $\alpha=0,05$ sehingga hipotesis alternatif (Ha) ditolak artinya tidak ada hubungan antara sosial ekonomi dengan rendahnya pemakaian kontrasepsi implan.

$$
\text { Responden yang menggunakan }
$$
kontrasepsi suntik memiliki sosial ekonomi yang cukup berjumlah 18 orang $(56,3 \%)$ dan yang memiliki sosial ekonomi kurang sebanyak 21 orang $(60 \%)$. Sedangkan responden yang menggunakan kontrasepsi pil memiliki sosial ekonomi yang cukup berjumlah 14 orang (40\%) dan yang memiliki sosial ekonomi yang kurang berjumlah 14 orang $(43,8 \%)$. Dari hasil uji statistik Chi-Square diperoleh nilai $\mathrm{p}=0,756>$ dari $\alpha=0,05$ sehingga hipotesis alternatif (Ha) ditolak artinya tidak ada hubungan antara sosial ekonomi dengan rendahnya pemakaian kontrasepsi implan.

Responden pengguna kontrasepsi suntik yang merasa tidak cemas berjumlah 30 orang $(55,6 \%)$ dan yang merasa cemas berjumlah 9 orang $(69,2 \%)$. Sedangkan responden pengguna 
kontrasepsi pil yang merasa tidak cemasi berjumlah 24 orang $(44,4 \%)$ dan yang merasa cemas berjumlah 4 orang $(30,8 \%)$. Dari hasil uji statistik Chi-Square diperoleh nilai $\mathrm{p}=0,369>$ dari $\alpha=0,05$ sehingga hipotesis alternatif (Ha) ditolak artinya tidak ada hubungan antara faktor kecemasan dengan rendahnya pemakaian kontrasepsi implan.

\section{PEMBAHASAN}

\section{Persepsi}

Berdasarkan hasil penelitian yang dilakukan di Puskesmas Minasa Upa Kota Makassar dari 67 sampel, menunjukkan ada hubungan berarti antara persepsi dengan rendahnya pemakaian kontrasepsi implan dengan nilai $\mathrm{p}=0,001$ ( $\mathrm{p}<0,05)$. Hal tersebut sejalan dengan penelitian yang dilakukan oleh (Siradjuddin \& Heremba, 2017) dengan judul Hubungan Persepsi dan Minat Ibu dengan Pemakaian Kontrasepsi Implan di Wilayah Puskesmas Jongaya Makassar. Penelitian ini juga sejalan dengan penelitian yang dilakukan oleh (Kristianti et al., 2020) dengan judul Persepsi dan Minat Menggunakan Alat Kontrasepsi Implan di Desa Ngasem Kediri.

Persepsi adalah interpretasi informasi berdasarkan pengalaman yang telah dialami oleh seseorang ataupun informasi yang didapatkan dari orang-orang terdekat, dalam hal ini, persepsi ibu tentang alat kontrasepsi, sangat mempengaruhi keputusan dalam memilih kontrasepsi yang aman. Sehingga hal ini menentukan apakah ibu bersedia menggunakan kontrasepsi atau tidak. Pemahaman ibu terhadap cara kerja, efek samping serta keuntungan suatu alat kontrasepsi akan memudahkan ibu dalam memilih alat kontrasepsi yang akan digunakan (Siradjuddin \& Heremba, 2017).

Asumsi peneliti mengenai hasil penelitian yang menunjukkan bahwa ada hubungan antara persepsi dengan rendahnya pemakaian kontrasepsi implan disebabkan kurangnya pengetahuan ibu mengenai kontrasepsi implan. Hal ini menyebabkan persepsi ibu cenderung negatif sehingga membuat beberapa ibu percaya bahwa implan yang telah dipasangkan dapat berpindah sendiri dari tempatnya. Dalam hal ini persepsi berpengaruh dalam keputusan ibu untuk tidak memilih kontrasepsi implan sebagai pilihan.

Persepsi ini dipengaruhi oleh pengetahuan seseorang, dalam hal ini dibutuhkan peran petugas kesehatan untuk memberikan pengetahuan yang baik terkait pemakaian kontrasepsi implan tersebut. Menurut penelitian (Wirda, 2021) bahwa kebanyakan responden mendapatkan informasi tersebut dari tetangga atau orang tua yang pernah menggunakannya. Hal ini dapat menyebabkan tidak adanya klarifikasi tentang kebenaran dari pengalaman tentang efek samping tersebut.

\section{Sosial Ekonomi}

Berdasarkan hasil penelitian yang dilakukan di Puskesmas Minasa Upa Kota Makassar dari 67 sampel, menunjukkan bahwa tidak ada hubungan antara sosial ekonomi dengan rendahnya pemakaian kontrasepsi implan dengan nilai $\mathrm{p}=0,756>$ dari $\alpha=0,05$. Penelitian ini tidak sejalan sejalan dengan penelitian yang dilakukan oleh (Hidayah \& Harahap, 2016) dengan judul Faktor-faktor yang Mempengaruhi Rendahnya Pengunaan KB Implan pada Wanita Usia Subur (WUS) di Desa Partihaman Saroha Kecamatan Padangsidimpuan Hutaimbaru Tahun 2016.

Menurut asumsi peneliti hal ini disebabkan karena masyarakat wilayah puskesmas Minasa Upa menggunakan layanan Kesehatan BPJS (Badan Penyelenggaraan Jaminan Sosial) sehingga pemasangan serta pelepasan implan ditanggung oleh layanan BPJS hal ini menyebabkan biaya yang dikeluarkan oleh ibu tidak terlalu besar. Selain itu jika ibu tidak memiliki BPJS, ibu masih bisa mengakses pelayanan gratis menggunakan JAMKESDA (Jaminan Kesehatan Daerah) jika ibu menggunakan KTP (Kartu Tanda Penduduk) wilayah Makassar. Jadi pelayanan pemasangan serta pelepasan implan tidak akan membebani ekonomi ibu.

\section{Faktor Kecemasan}

Berdasarkan hasil penelitian yang dilakukan di Puskesmas Minasa Upa Kota Makassar dari 67 sampel menunjukkan bahwa tidak ada hubungan antara faktor kecemasan dengan rendahnya pemakaian kontrasepsi implan dengan nilai $\mathrm{p}=0,369>$ dari $\alpha=0,05$. Hal ini berhubungan dengan respon ibu yang rata-rata hanya berada di tahap merasa takut dengan prosedur pemasangan implan sehingga pada tahap ini ibu tidak dikategorikan mengalami kecemasan.

Perasaan takut yang dirasakan oleh ibu disebabkan oleh ketakutan terhadap rasa nyeri 
yang ditimbulkan saat penyisipan implan berlangsung. Selain itu ibu merasa takut jika implan yang dipasangan akan berpindah dan menghilang di dalam tubuh. Perasaan takut ini berkaitan dengan kurangnya pengetahuan serta pengalaman ibu mengenai prosedur pemasangan implan. Menurut (Rasyid, 2019) kecemasan calon akseptor sebelum pemberian informasi prosedur pemasangan implan juga dapat disebabkan karena terjadinya perubahan emosi atau perasaan khawatir tentang suatu hal yang akan terjadi.

Walaupun ibu merasa tidak cemas dengan prosedur pemasangan implan tapi rasa takut yang dialami oleh ibu mempengaruhi keputusan ibu dalam memilih kontrasepsi. Ketakutan akan rasa nyeri yang timbul membuat ibu tidak tertarik menggunakan kontrasepsi implan. Menurut (Ruspawan \& Rahayu, 2017) perasaan takut sangat berpengaruh dalam mendukung responden untuk mengambil suatu keputusan, jika persepsi responden sudah merasa takut maka kemauan untuk menggunakan implan sangat rendah.

\section{KESIMPULAN DAN SARAN}

Berdasarkan hasil penelitian dan pembahasan tentang faktor-faktor yang mempengaruhi rendahnya pemakaian kontrasepsi implan di Puskesmas Minasa Upa Kota Makassar tahun 2020, maka dapat disimpulkan bahwa ada hubungan antara persepsi dengan rendahnya pemakaian kontrasepsi implan di Puskesmas Minasa Upa Kota Makassar sedangkan faktor sosial ekonomi dan faktor kecemasan tidak memiliki hubungan.

Bagi petugas Kesehatan diharapkan melakukan penyuluhan yang rutin mengenai kontrasepsi khususnya implan, dengan memberikan edukasi diharapkan dapat menambah pengetahuan ibu sehingga persepsi negatif terhadap kontrasepsi implan dapat diatasi. Dalam hal ini ibu bisa lebih percaya menggunakan kontrasepsi implan. Selain itu peneliti selanjutnya diharapkan dapat menemukan faktor-faktor lain yang mempengaruhi rendahnya pemakaian kontrasepsi implan.

\section{DAFTAR PUSTAKA}

Affandi, B., Adriaansz, G., Rusdianto, E., \& Koesno, H. (2014). Buku Panduan Praktis Pelayanan Kontrasepsi (Edisi keti). PT Bina Pusaka Sarwono
Prawirohardjo.

BKKBN. (2017). Peraturan Kepala Badan Kependudukan dan Keluarga Berencana Nasional. https://jdih.bkkbn. go.id/ produk/detail/?id=29.

Dinkes Kota Makassar. (2017). Data dan Informasi Profil Kesehatan Provinsi Sulawesi Selatan.

Hidayah, A., \& Harahap, Y. V. (2016). FaktorFaktor Yang Mempengaruhi Rendahnya Pengetahuan KB Implant Pada Wanita Usia Subur (WUS) Di Desa Partihaman Sarona Kecamatan Padang Sidimpuan Hutaimanbaru. Jurnal Kesehatan Ilmiah Indonesia, 1(3), 47-55.

Kemenkes RI. (2019). Profil Kesehatan Indonesia. http://www.kemenkes.go.id.

Kristianti, S., Mediawati, M., \& Rohmawati, D. (2020). Persepsi dan Minat Menggunakan Alat Kontrasepsi Implan di Desa Ngasem Kediri. Jurnal Kebidanan Kestra, 3(1), 32-38. https://doi.org/ 10.35451/ jkk.v3i1.464.

Lestari, A., \& Rachmadini, A. F. (2019). Faktor-Faktor yang Berhubungan dengan Rendahnya Minat Ibu terhadap Penggunaan Implan. Jurnal Ilmiah Kebidanan Indonesia, 9(04), 169-174. https://doi.org/10.33221/jiki.v9i04.418.

Mardiyono. (2017). Kampung KB Sebagai Upaya Pemberdayaan Masyarakat/ Keluarga di Jawa Timur (Studi di Kota Malang dan Kabupaten Bondowoso). Jurnal Cakrawala, 11(2), 129-136. http://cakrawalajournal.org/index.php/cak rawala/article/viewFile/13/13.

Rahmi, A. A., \& Hadi, E. N. (2020). Determinan Pemilihan Implan Pada Pasangan Usia Subur Di Kecamatan Medan Petisah. Perilaku Dan Promosi Kesehatan: Indonesian Journal of Health Promotion and Behavior, 2(2), 7. https://doi.org/10.47034/ppk.v2i2.4144.

Rasyid, P. S. (2019). Pengaruh Pemberian Informasi Prosedur Pemasangan Implant Terhadap Tingkat Kecemasan Calon Akseptor Implan di Kota Gorontalo. Jurnal Nasional Ilmu Kesehatan, 1(3), 116.

Ruspawan, I. D. M., \& Rahayu, I. G. A. D. P. (2017). Persepsi dan Sumber Ekonomi yang Mempengaruhi Rendahnya WUS Memilih Implant Sebagai Alat Kontrasepsi. Jurnal Gema Keperawatan, 
10(2), 169-176.

Saad, R. (2018). Faktor-Faktor yang Berhubungan dengan Penggunaan Alat Kontrasepsi Implant di Puskesmas Batulappa kab. Pinrang tahun 2018. Jurnal Ilmiah Kesehatan Iqra, 6(1), 7076. https://stikesmu-sidrap.e-journal.id/ JIKI/article/download/64/52.

Siradjuddin, Y., \& Heremba, S. (2017). Hubungan Persepsi dan Minat Ibu dengan Pemakaian Kontrasepsi Implan di Wilayah Puskesmas Jongaya Makassar. Jurnal Ilmiah Keperawatan Dan Kebidanan Holistic Care (JIKKHC), 02(01).
Wirda, W. (2021). Gambaran Pengetahuan Akseptor KB Implant Tentang Efek Samping Alat Kontrasepsi Impan di Puskesmas Talang Bakung, Kota Jambi Tahun 2021. Jurnal Ekonomi Manajemen Sistem Informasi, 2(4), 490-500. https://doi.org/10.31933/jemsi.v2i4.453.

World Health Organization (WHO). (2015). WHO statement on progestogen-only implants (Vol. 3018, Issue 15). http://apps.who.int/iris/bitstream/10665/1 90063/1/WHO_RHR_15.20_eng.pdf?ua= 1. 